\title{
Studies on the effectiveness of oral pellet vaccine in improving egg production and egg quality in desi chicken
}

\author{
T. Lurthu Reetha ${ }^{1}$, J. Johnson Rajeswar ${ }^{2}$, T. J. Harikrishnan ${ }^{3}$, K. Sukumar ${ }^{4}$, P. Srinivasan ${ }^{5}$ and J. John Kirubakaran ${ }^{6}$
}

1. Tamil Nadu Veterinary and Animal Sciences University - Regional Research, Pudukkottai - 622 004, Tamil Nadu, India; 2. Department of Veterinary Microbiology, Veterinary College and Research Institute, Tirunelveli - 627 001, Tamil Nadu, India; 3. Directorate of Research, Tamil Nadu Veterinary and Animal Sciences University, Chennai - 600 051, Tamil Nadu, India; 4. Department of Veterinary Microbiology, Veterinary College and Research Institute, Namakkal - 637002,

Tamil Nadu, India; 5. Veterinary University Training and Research Centre, Nagapattinam, Tamil Nadu, India;

6. Department of Veterinary Microbiology, Madras Veterinary College, Chennai - 600 007, Tamil Nadu, India.

Corresponding author: T. Lurthu Reetha, e-mail: drreethaarul@gmail.com,

JJR:dr_johnswar@yahoo.com,TJH: tjhkrishnan@gmail.com, KS: drksugu@gmail.com, PS: srinipat2004@yahoo.com, JJK: jjohnk@gmail.com

Received: 31-03-2016, Accepted: 19-07-2016, Published online: 24-08-2016

doi: 10.14202/vetworld.2016.900-903 How to cite this article: Reetha TL, Rajeswar JJ, Harikrishnan TJ, Sukumar K, Srinivasan P, Kirubakaran JJ (2016) Studies on the effectiveness of oral pellet vaccine in improving egg production and egg quality in desi chicken, Veterinary World, 9(8): 900-903.

\begin{abstract}
Aim: To study the effect of Newcastle disease (ND) oral pellet vaccine in egg production and egg quality in desi chicken.

Materials and Methods: The study was conducted at Veterinary University Training and Research Centre, Tiruchirapalli, Tamil Nadu. A total of 48-day-old desi chicks obtained from a private hatchery in Namakkal, Tamil Nadu, were maintained under cage system of rearing up to 52 weeks of age as per standard management practices. All the 48 chicks were divided into six groups having eight chicks in each group were subjected to different treatment regimes. All the birds were challenged at 52 weeks of age with $0.5 \mathrm{ml}$ dose of $10^{4.0} \mathrm{egg}$ infectious dose 50 virulent ND field virus. 10 eggs from each group were randomly collected during the last 3 days of 8 weeks interval period from 28 to 52 weeks of age and were used to measure the egg quality parameters. The production performance of each group was assessed at 4 weeks interval period from 25 to 52 weeks of age.
\end{abstract}

Results: In all the six treatment groups with respect to egg production, no significant difference ( $\mathrm{p} \geq 0.05$ ) was noticed from 25 to 52 weeks of age. Similarly, in egg weight, egg shape index and specific gravity, no significant difference ( $\mathrm{p} \geq 0.05)$ was noticed from 28 to 52 weeks of age.

Conclusion: From this study, it is concluded that the administration of ND oral pellet vaccine to desi chicken does not affect the egg production performance, egg weight, egg shape index, and specific gravity of egg.

Keywords: effectiveness, egg production, egg quality, desi chicken, oral pellet vaccines.

\section{Introduction}

Newcastle disease (ND) is one of the major viral diseases of poultry causing great economic losses to the poultry industry [1]. ND remains a constant threat to the poultry industry and is a limiting disease for poultry producers worldwide [2]. The native chicken varieties adopted in free-range backyard conditions contribute about $11 \%$ of total egg production in India [3]. Village poultry plays a key and often undervalued role in a rural development in many poor rural households and is a global asset for many millions who live below the poverty line [4].

A vaccination of chickens has remained as the principal method to control this disease $[5,6]$. Control of ND primarily consists of vaccination of flocks and culling of infected or likely infected birds [7]. An effective

Copyright: Reetha, et al. Open Access. This article is distributed under the terms of the Creative Commons Attribution 4.0 International License (http://creativecommons.org/licenses/ by/4.0/), which permits unrestricted use, distribution, and reproduction in any medium, provided you give appropriate credit to the original author(s) and the source, provide a link to the Creative Commons license, and indicate if changes were made. The Creative Commons Public Domain Dedication waiver (http:// creativecommons.org/publicdomain/zero/1.0/) applies to the data made available in this article, unless otherwise stated. vaccination with conventional vaccines involves maintaining a cold chain, catching and handling individual birds, using skilled vaccinators and repeating the whole procedure sufficiently often to ensure that every bird receives at least two doses of vaccine at different times [8]. The selection of an ND vaccine for use in rural chicken will depend on the local conditions in each country. Selection criteria will include - Ease of use, cost, thermostability, immunogenicity, availability, and transportability. In circumstances where the cold chain is weak or absent, the only reliable option will be the use of thermostable ND vaccines [9].

Hence, this study was conducted with the objective to observe the effectiveness of thermostable Tamil Nadu Veterinary and Animal Sciences University (TANUVAS) oral pellet vaccine in improving egg production and egg quality in desi chicken.

\section{Materials and Methods}

\section{Ethical approval}

All animal procedures were performed in accordance with Institutional Animal Ethical Committee regulations (Approval No. 8/2012 of IAEC dated 10.08.2012). 


\section{Birds and experimental design}

The study was carried out at Veterinary University Training and Research Centre, Tiruchirapalli, Tamil Nadu. A total of 48-day-old desi chicks obtained from a private hatchery in Namakkal, Tamil Nadu, were maintained under cage system of rearing up to 52 weeks of age under standard management practices. All the 48 chicks were divided into six groups having eight chicks in each group. First group (T1) served as unvaccinated control, second group (T2) was primed with commercially available thermostabilized D58 vaccine followed by booster with TANUVAS oral pellet vaccine, third group (T3) was primed as well as boosted with TANUVAS oral pellet vaccine, fourth group (T4) was primed with RDV'F' followed by booster with commercial vaccines (LaSota and R2B), fifth group (T5) was primed with commercially available thermostabilized D58 vaccine followed by booster with commercial vaccines (LaSota and R2B), sixth group (T6) was primed with TANUVAS oral pellet vaccine followed by booster with commercial vaccines (LaSota and R2B). All the birds were challenged at 52 weeks of age with $0.5 \mathrm{ml}$ dose of $10^{4.0}$ egg infectious dose $50\left(\mathrm{EID}_{50}\right)$ virulent ND field virus.

The TANUVAS oral pellet vaccine produced was standardized for safety, purity, and potency as per the specifications $[10,11]$. In potency test, 10 unprimed chickens aged 6 weeks old were vaccinated with oral pellet vaccine ad libitum and hemagglutination inhibition titer was recorded on 21 days post vaccination. If the flock average was more than 23 , the batch of vaccine was considered as potent. To reconfirm this, all birds were challenged with $10^{6} \mathrm{EID}_{50}$ of virulent velogenic virus obtained from Institute of Veterinary Preventive Medicine, Ranipet. All birds withstood the challenge. The different batches of vaccine produced passed this test and proved to be potent. In safety test, 10 unprimed birds were given more than minimum dose (vaccine pellets given ad libitum) and the birds were observed for 14 days. No local and systemic reactions were noticed. The different batches of vaccine produced passed this test and proved to be safe. In purity test, the seed was tested for bacterial and fungal contaminants and infectious bronchitis virus and found to be pure. The vaccine did not contain any aerobic or anaerobic bacteria and fungi. The vaccine was found to be potent, and the vaccinated birds withstood virulent virus challenge.

\section{Sample collection and analysis}

The production performance of each group was assessed at 4 weeks interval period from 25 to 52 weeks of age and percent hen-day egg production was worked out. 10 eggs per treatment were randomly collected to study the physical qualities of egg like egg weight, shape index, and specific gravity were assessed by standard procedure.

\section{Statistical analysis}

An analysis of variance with one factor was used to examine the effects of different types of vaccine on egg production, egg weight, egg shape index, and egg specific gravity. The values presented were expressed by assigned average standard error of the mean. In the case of significant difference, Tukey's HSD test was used to separate homogeneous groups at a significant level of 5\%.

\section{Results and Discussion}

Poultry, especially chickens, are the most widely reared species worldwide and are found in great numbers [12]. Poultry production has an important economic, social and cultural benefit and plays a significant role in family nutrition in the developing countries [13]. Egg quality is the general term which refers to general standards which define both internal and external quality such as egg weight, egg length, width, egg index, shell weight, shell thickness, albumin height, albumin width, yolk height, yolk index, and haugh unit [14].

Village poultry farmers have less awareness to sort eggs for different purposes such as for hatching, marketing and home consumption purposes [15]. The egg quality could be affected by the production system among others [16]. Free range chicken production represents an important system for providing high-quality protein and income to the growing human population especially for the women [17]. Due to the low production (annual egg production: 50-60 nos.) nature of desi birds, their contribution to the total egg output was almost static for the last few decades [18].

The thermostable vaccine induces protective immunity among free-range chickens when correctly applied. It is cheaper and thus makes it affordable to all farmers to use and it is easy to administer by farmers. It contributes to the improvement of household food security in many developing countries the control of ND will contribute to improved village poultry production. The thermostable vaccine of ND-I 2 and V4 (Australian strains) is used to control ND in village chickens in Africa and Asia [19].

In this study with respect to egg production performance, no significant difference was noticed up to 52 weeks of age $(p \geq 0.05)$. The overall mean of percent egg production in T2 and T6 is similar and also T1, T3 and T5 are similar followed by T4 (Table-1). In earlier study, similar finding was reported [20] that average annual egg production of the native chicken was 30-60 eggs under village conditions and that this could be improved to $80-100$ eggs on-station by proper vaccination.

In all the six treatment groups with respect to egg weight, no significant difference was noticed from 28 to 36 weeks of age, 37 to 44 weeks of age, and 45 to 52 weeks of age $(\mathrm{p} \geq 0.05)$. The mean egg weight in 45-52 weeks of age was maximum followed by 37-44 weeks of age and 28-36 weeks of age (Table-2). The mean egg weight of $38 \mathrm{~g}$ and $40.73 \mathrm{~g}$ was reported in Fulani-ecotype native chicken eggs [21].

In this study with respect to egg shape index, no significant difference was noticed between different 
treatment groups from 28 to 36 weeks of age, 37 to 44 weeks of age, and 45 to 52 weeks of age ( $\geq 0.05)$. The mean egg shape index of all treatment groups ranged from $77.14 \pm 0.23$ to $77.83 \pm 0.10$ during 28 to 52 weeks of age (Table-3). In another recent study [22] reported that the egg shape index of naked neck birds as $77.51 \pm 1.80$.
In this study with respect to specific gravity of egg, no significant difference was noticed from 28 to 36 weeks of age, 37 to 44 weeks of age, and 45 to 52 weeks of age $(p \geq 0.05)$. The mean specific gravity of all treatment groups ranged from $1.130 \pm 0.009$ to $1.186 \pm 0.023$ during 28 to 52 weeks of age (Table-4). The external and internal egg quality traits of local hill

Table-1: Effect of different ND vaccine and vaccination regimen in desi chicken on percent hen day egg production.

\begin{tabular}{|c|c|c|c|c|c|c|c|c|c|}
\hline \multirow[t]{2}{*}{ Treatment } & \multicolumn{7}{|c|}{ Mean egg production } & \multirow{2}{*}{$\begin{array}{c}\text { Overall mean } \\
\begin{array}{c}\text { Percent egg } \\
\text { production }\end{array}\end{array}$} & \multirow{2}{*}{$\begin{array}{l}\text { Average egg } \\
\text { number per bird }\end{array}$} \\
\hline & $\begin{array}{l}25-28 \\
\text { weeks }\end{array}$ & $\begin{array}{l}29-32 \\
\text { weeks }\end{array}$ & $\begin{array}{l}\text { 33-36 } \\
\text { weeks }\end{array}$ & $\begin{array}{l}\text { 37-40 } \\
\text { weeks }\end{array}$ & $\begin{array}{l}\text { 41-44 } \\
\text { weeks }\end{array}$ & $\begin{array}{l}45-48 \\
\text { weeks }\end{array}$ & $\begin{array}{l}\text { 49-52 } \\
\text { weeks }\end{array}$ & & \\
\hline T1 - Control & 12.50 & 19.64 & 23.21 & 21.43 & 20.54 & 19.64 & 18.75 & 18.75 & 36.75 \\
\hline $\begin{array}{l}\text { T2 - D58 and oral pellet } \\
\text { vaccine }\end{array}$ & 13.39 & 19.64 & 22.32 & 21.43 & 20.54 & 20.54 & 19.64 & 19.64 & 38.50 \\
\hline T3 - Oral pellet vaccine & 14.29 & 20.54 & 24.11 & 22.32 & 20.54 & 19.64 & 18.75 & 18.75 & 36.75 \\
\hline T4 - Commercial vaccine & 14.29 & 19.64 & 23.21 & 21.43 & 19.64 & 18.75 & 17.86 & 17.86 & 35.00 \\
\hline $\begin{array}{l}\text { T5 - D58 and commercial } \\
\text { vaccine }\end{array}$ & 14.29 & 19.64 & 22.32 & 21.43 & 20.54 & 19.64 & 18.75 & 18.75 & 36.75 \\
\hline $\begin{array}{l}\text { T6 - Oral pellet vaccine and } \\
\text { commercial vaccine }\end{array}$ & 14.29 & 19.64 & 22.32 & 21.43 & 20.54 & 20.54 & 19.64 & 19.64 & 38.50 \\
\hline $\mathrm{p}$ value & 0.16 & & & & & & & & \\
\hline
\end{tabular}

ND: Newcastle disease

Table-2: Effect of different ND vaccine and vaccination regimen in desi chicken on egg weight ( $g)(\mathrm{mean} \pm \mathrm{SE})$.

\begin{tabular}{lccc}
\hline Treatment & \multicolumn{3}{c}{ Mean egg weight (g) } \\
\cline { 2 - 4 } & $\mathbf{2 8 - 3 6}$ weeks & $\mathbf{3 7 - 4 4}$ weeks & $\mathbf{4 5 - 5 2 ~ w e e k s ~}$ \\
\hline T1 - Control & $38.22 \pm 0.11$ & $38.86 \pm 0.15$ & $39.88 \pm 0.17$ \\
T2 - D58 and oral pellet vaccine & $38.12 \pm 0.19$ & $38.87 \pm 0.18$ & $39.87 \pm 0.19$ \\
T3 - Oral pellet vaccine & $38.25 \pm 0.18$ & $38.84 \pm 0.16$ & $39.94 \pm 0.17$ \\
T4 - Commercial vaccine & $38.07 \pm 0.17$ & $38.98 \pm 0.18$ & $39.98 \pm 0.20$ \\
T5 - D58 and commercial vaccine & $38.04 \pm 0.17$ & $38.84 \pm 0.17$ & $40.01 \pm 0.19$ \\
T6 - Oral pellet vaccine and commercial vaccine & $37.94 \pm 0.12$ & $38.94 \pm 0.15$ & $40.05 \pm 0.20$ \\
p value & 0.75 & 0.97 & 0.82 \\
\hline
\end{tabular}

Each value is a mean of 10 observations. SE: Standard error, ND: Newcastle disease

Table-3: Effect of different ND vaccine and vaccination regimen in desi chicken on egg shape index (mean $\pm \mathrm{SE})$.

\begin{tabular}{lccc}
\hline Treatment & \multicolumn{3}{c}{ Mean egg shape index } \\
\cline { 2 - 4 } & $\mathbf{2 8 - 3 6}$ weeks & $\mathbf{3 7 - 4 4}$ weeks & $\mathbf{4 5 - 5 2}$ weeks \\
\hline T1 - Control & $77.61 \pm 0.08$ & $77.14 \pm 0.23$ & $77.38 \pm 0.21$ \\
T2 - D58 and oral pellet vaccine & $77.32 \pm 0.20$ & $77.66 \pm 0.15$ & $77.78 \pm 0.16$ \\
T3 - Oral pellet vaccine & $77.43 \pm 0.22$ & $77.41 \pm 0.17$ & $77.83 \pm 0.10$ \\
T4 - Commercial vaccine & $77.71 \pm 0.06$ & $77.57 \pm 0.14$ & $77.65 \pm 0.18$ \\
T5 - D58 and commercial vaccine & $77.72 \pm 0.11$ & $77.29 \pm 0.21$ & $77.37 \pm 0.10$ \\
T6 - Oral pellet vaccine and commercial vaccine & $77.66 \pm 0.09$ & $77.58 \pm 0.14$ & $77.47 \pm 0.12$ \\
p value & 0.18 & 0.36 & 0.16 \\
\hline
\end{tabular}

Each value is a mean of 10 observations. SE: Standard error, ND: Newcastle disease

Table-4: Effect of different ND vaccine and vaccination regimen in desi chicken on egg specific gravity (mean \pm SE).

\begin{tabular}{lccc}
\hline Treatment & \multicolumn{3}{c}{ Mean specific gravity } \\
\cline { 2 - 4 } & $\mathbf{2 8 - 3 6}$ weeks & $\mathbf{3 7 - 4 4}$ weeks & $\mathbf{4 5 - 5 2}$ weeks \\
\hline T1 - Control & $1.131 \pm 0.004$ & $1.158 \pm 0.007$ & $1.164 \pm 0.008$ \\
T2 - D58 and oral pellet vaccine & $1.130 \pm 0.009$ & $1.165 \pm 0.005$ & $1.164 \pm 0.004$ \\
T3 - Oral pellet vaccine & $1.150 \pm 0.014$ & $1.163 \pm 0.006$ & $1.131 \pm 0.019$ \\
T4 - Commercial vaccine & $1.174 \pm 0.024$ & $1.145 \pm 0.004$ & $1.162 \pm 0.006$ \\
T5 - D58 and commercial vaccine & $1.149 \pm 0.008$ & $1.152 \pm 0.008$ & $1.161 \pm 0.008$ \\
T6 - Oral pellet vaccine and commercial vaccine & $1.186 \pm 0.023$ & $1.144 \pm 0.006$ & $1.142 \pm 0.012$ \\
p value & 0.115 & 0.078 & 0.162 \\
\hline
\end{tabular}

Each value is a mean of 10 observations. SE: Standard error, ND: Newcastle disease 
fowl in Uttarakhand under an intensive system of rearing and recorded that the specific gravity as 1.08 [23].

The challenged birds were observed 10 days for the development of clinical signs, mortality, and lesions. No mortality was observed in any of the vaccinated group whereas $100 \%$ mortality was recorded in the unvaccinated control group during the observation period. The challenged control birds exhibited clinical signs like greenish white diarrhea and torticollis. Post mortem examination revealed petechial hemorrhages on the tip of proventriculus papillae.

\section{Conclusion}

From this study, it is concluded that the administration of ND oral pellet vaccine to desi chicken does not affect the egg production performance and other egg quality traits. The thermostable TANUVAS oral pellet vaccine had found to be more advantageous, and the vaccine can support poultry farmers to get rid from ND globally.

\section{Authors' Contributions}

This study was a part of TLR's original research work during Ph.D. thesis program. JJR, TJH and KS had designed the plan of work. PS helped the laboratory work. JJK tested the safety of the vaccine. TLR, JJ, TJH, KS, PS and JJK analyzed the results. All the authors read and approved the final manuscript.

\section{Acknowledgments}

The authors express their gratitude to TANUVAS for granting permission to carry out this doctoral research on part time basis. This research work was carried out by using Tamil Nadu Veterinary and Animal Sciences University grant.

\section{Competing Interests} interests.

The authors declare that they have no competing

\section{References}

1. Geetha, M., Gunaseelan, L., Ganesan, P.I., Kumanan, K. and Selvaraju, G. (2014) Role of free living birds as reservoirs of Newcastle disease virus infection. Int. J. Environ. Sci. Technol., 3(4): 1450-1454.

2. Cattoli, G., Susta, L., Terregino, C. and Brown, C. (2011) Newcastle disease: A review of field recognition and current methods of laboratory detection. J. Vet. Diagn. Invest., 23: 637-656.

3. Kumaresan, A., Bujarbaruah, K.M., Pathak, K.A., Chettri, B., Ahmed, S.K. and Haunshi, S. (2008) Analysis of a village chicken production system and performance of improved dual purpose chickens under a subtropical hill agro-ecosystem in India. Trop. Anim. Health Prod., 40: 395-402.

4. Gueye, E.F. (2000) The role of family poultry in poverty alleviation, food security and the promotion of gender equality in rural Africa. Outlook Agric., 29(2): 129-136.

5. Okwor, E.C., Eze, D.C., Anyanwu, M.U., Okpe, C.B. and Eze, P.C. (2013) Effects of mixed vaccinations against
Newcastle disease and infectious bursal disease on immune response feed consumption and weight gain in broilers. J. Agric. Vet. Sci., 6: 63-68.

6. El-Mahdy, S.S., Hayam, F., Abd El-Wanis, N.A. and Hamoud, M.M. (2013) Comparative studies between different commercial types of live infectious bursal disease [IBD] vaccine strains in Egypt. Am. J. Vet. Res., 1: 113-129.

7. Senne, D.A., King, D.J. and Kapczynski, D.R. (2004) Control of Newcastle disease by vaccination. Dev. Biol. (Basel), 119: 165-170.

8. Nasser, M., Lohr, J.E., Mebratu, G.Y., Zessin, K.H., Baumann, M.P.O. and. Ademe, Z. (2000) Oral Newcastle disease vaccination trials in Ethiopia. Avian Pathol., 29: 27-34.

9. Ideris, A., Ibrahim, A.L., Spradbrow, P.B. and Hung Seng, C. (1987) Development of food pellet Newcastle disease vaccine. In: Copland, J.W., editor. Newcastle Disease in Poultry: A New Food Pellet Vaccine. ACIAR, Canberra. p20-23.

10. FAO. (1991) Manual on production of Marek's disease. Gumboro Disease and Inactivated Newcastle Disease Vaccines. FAO Animal Production and Health Paper. p89.

11. OIE. (2000) Manual of Diagnostic Tests and Vaccines for Terrestrial Animals. Paris: OIE Publication; 2000.

12. Moreki, J.C., Dikeme, K. and Poroga, B. (2010) The role of village poultry in food security and HIV/AIDS mitigation in Chobe district of Botswana. Livest. Res. Rural. Dev., 22(10). Available from: http://www.lrrd.org/lrrd22/3/ more22055.htm. Accessed on 05-01-2016.

13. Tadesse, D., Singh, H., Mengistu, A., Esatu, W. and Dessie, T. (2013) Study on productive performances and egg quality traits of exotic chickens under village production system in East Shewa, Ethiopia. Afr. J. Agric. Res., 8(13): 1123-1128.

14. Bobbo, A.G., Baba, S.S. and Yahaya, M.S. (2013) Egg quality characteristic of three phenotypes of local chickens in Adamawa state. J. Agric. Vet. Sci., 4: 13-21.

15. Mengesha, M., Tamir, B. and Dessie, T. (2011) Village chicken constraints and traditional management practices in Jamma District, South Wollo, Ethiopia. Livest. Res. Rural Dev., 23: 37. Available from: http//www.lrrd.org/lrrd23/2/ meng23037.htm. Accessed on 07-01-2016.

16. Tadesse, D., Esatu, W., Girma, M. and Dessie, T. (2015) Comparative study on some egg quality traits of exotic chickens in different production systems in East Shewa, Ethiopia. Afr. J. Agric. Res., 10(9): 1016-1021.

17. Gueye, E. (2009) The role of networks in information dissemination to family poultry farmers. Worlds Poult. Sci. J., 65: 115-123.

18. Pathak, P.K. and Nath, B.G. (2013) Rural poultry farming with improved breed of backyard chicken. J. World's Poult. Res., 3(1): 24-27.

19. Adwar, T. and Lukesova, D. (2008) Evaluation of thermostable vaccines against Newcastle disease in village chicken used in tropics and subtropics. Agric. Trop. Subtrop., 41(2): 74-79.

20. Bigbee, D.G. (1965) The Management of the Native Chickens of Ethiopia. Miscellaneous Publication No.5. HSIU, College of Agriculture, Alemaya.

21. Brannang, E. and Person, S. (1990) Ethiopian Animal Husbandry. Uppsala, Sweden. p127.

22. Ali, A. and Anjun, R. (2013) Evaluation of egg quality traits among different breeds/strains of chicken locally available in Pakistan. J. Livest. Prod., 1: 16-23.

23. Shive, K., Blavir, S., Yadav, S.N., Bharadwaj, R.K. and Kumar, D. (2008) Studies on external and internal egg quality traits of local hill fowl under intensive system of rearing. Indian J. Poult. Sci., 43: 375-377. 